(C2020, Elsevier. Licensed under the Creative Commons Attribution-NonCommercialNoDerivatives 4.0 International http://creativecommons.org/about/downloads

cc) $(1) \Theta$ 
Founders' social identity and entrepreneurial self-efficacy amongst nascent entrepreneurs: a configurational perspective

Chris Hand $^{\text {la }}$, Marfuga Iskandarova ${ }^{2}$ and Robert Blackburn ${ }^{3}$

1. Department of Strategy Marketing and Innovation, Kingston Business School, Kingston Hill, Kingston upon Thames, Surrey, KT2 7LB, UK.

2. Small Business Research Centre, Kingston Business School, Kingston Hill, Kingston upon Thames, Surrey, KT2 7LB, UK.

3. University of Liverpool Management School, University of Liverpool Chatham Street, Liverpool, L69 7ZH

a. Corresponding author

Accepted for publication in the Journal of Business Venturing Insights 


\title{
Founders' social identity and entrepreneurial self-efficacy amongst nascent entrepreneurs: a configurational perspective
}

\begin{abstract}
Entrepreneurial self-efficacy (ESE) is a central concept in entrepreneurship research. We argue that although using advanced techniques, previous analyses of ESE have not reflected the complexity of the concept's relationship with its antecedents. In contrast to prior studies, we examine the relationship between ESE and entrepreneurial social identity using fuzzy set qualitative comparative analysis. Using such a configurational perspective shows that different combinations of age, gender, entrepreneurial activity, entrepreneurial learning and perceived controllability emerge as the core influences on ESE.
\end{abstract}

\section{Introduction}

Entrepreneurial Self-Efficacy (ESE) refers to an individual's belief in their ability to successfully perform entrepreneurial roles and tasks (e.g. Chen, Greene and Crick, 1998). ESE has emerged as a central concept in entrepreneurial research (e.g. Dalborg and Wincent, 2014; Miao et al. 2017; Kevill et al., 2017) and influences entrepreneurial intention, motivation and performance.

The aim of this paper is to examine the relationship between founder's social identity and ESE, revisiting Brandle et al's (2018) findings adopting a configurational perspective. The replicability of research findings has attracted increased attention in management, with a number of calls for replication studies, including a recent (2018) call in JBVI. Successful replications not only confirm earlier findings, but also allow those findings to be generalized more broadly. Walker et al. (2018) identify different categories of replication defined by the populations, measures and analysis used. Investigating the same topic with a different 
population and different analysis (but the same measures), as this paper does, falls into their generalization and extension category. A key aspect of our extension is the form of analysis adopted. Our analysis allows for different configurations of variables to lead to the same outcome and follows an approach advocated by Woodside (2016).

A number of antecedents of ESE have been identified including social identity, demographics and other individual differences, prior experience and education and cultural and institutional environment. However, the dominant approach to investigation has been to use linear models. We use fuzzy set qualitative comparative analysis (FSQCA) to allow us to accommodate causal complexity, which is a central challenge in management and organisational research (Misagyi et al., 2016). Our rationale for the approach is that there are multiple, equally effective, configurations of antecedents of ESE. We argue that social identities combine with other variables (e.g. perceived controllability) in multiple ways to influence ESE. We identify four combinations of antecedents that are associated with enhanced ESE and identify the core and peripheral conditions in each. By doing so we contribute to the literature by demonstrating that the effect of social identity on ESE should not be considered in isolation from other factors. Rather ESE depends on how social identity combines with other antecedents. Furthermore, we find that some of the variables previously used as control variables play a much more central role than social identity.

\section{Nascent entrepreneurs' entrepreneurial self-efficacy and social identity}

Self-efficacy refers to individuals' judgements about their own ability complete courses of actions to achieve a desired outcome (e.g. Bandura, 1997). As such, rather than relating to the level of skill possessed, it captures belief in the ability to use those skills to achieve a desired outcome. ESE (e.g. Boyd and Vozikis, 1994) relates specifically to a perceived ability to respond to an entrepreneurial challenge. Along with general self-efficacy, 
ESE has been found to be a key driver of entrepreneurial intentions (Schmutzler et al, 2018). ESE is particularly important for nascent entrepreneurs, who may lack direct experience and hence confidence in their abilities. However, too much ESE can have a detrimental effect and lead to over-optimistic decision-making and increased risk-taking.

Social identity (Tajfel, 1972) relates to how the sense of self is influenced by perceived membership of a social group. Social identity influences the motivations important to an individual. In turn, behaviours and actions that reinforce that identity act as a source of self-worth. Thus, a business founder's social identity will have an effect on the motivations and opportunities they choose to pursue and the type of value they create.

Fauchert and Gruber (2011) propose three founders' social identity types: Darwinian, Communitarian and Missionary. Darwinians are driven by competition and profit seeking, seeing their competitors as the main point of reference and valuing a professional approach to running their firms. Communitarians are driven more by a desire to contribute to a community they identify with and have interests in their product or service beyond a purely commercial interest. Missionaries, are driven by a desire to promote social change through the ventures they create, with society at large being their point of reference.

Social Cognitive Theory (SCT) (e.g. Bandura, 1997) provides a framework to understand how ESE develops via different pathways such as vicarious learning, mastery experiences and social persuasion (Newman et al. 2018). Vicarious learning refers to learning by observation, rather than direct experience. Mastery experience by contrast is learning from direct successful experience. Lastly social persuasion refers to direct encouragement (or discouragement). Drawing on this, Brändle et al. (2018), argue that different forms of founder's social identity will be associated with different levels of ESE. Darwinians are likely to perceive higher levels of ESE via 1) professional competence and education; 2) they are more likely to have close role models (being the "stereotypical" 
entrepreneur), 3) facing fewer sources of anxiety as their interests focus on their own performance. Communitarians gain a sense of accomplishment and authenticity from their prior knowledge and standing in the community. This may be countered by a degree of responsibility for and not wishing to disappoint their community. Such anxieties lead to a more ambiguous relationship between Communitarian social identity and ESE. Missionaries are expected to perceive ESE as lower as they set themselves very high targets, to change how the world operates, and may feel greater anxiety if they fail to meet this aim.

Alongside social identity, a number of other factors have been found to influence ESE. Newman et al. (2019), identify six broad groups of antecedents of ESE: cultural and institutional environment, firm characteristics, education and training, work experience, role models and mentors and lastly individual differences. As we are revisiting Brändle et al.'s findings, we include the same set of explanatory variables alongside social identity. Whilst self-efficacy relates to perceived ability to perform a particular activity, perceived controllability is a more general perception of ability to perform a behaviour (e.g. Ajzen, 2002). Following from this, ESE will be reduced if nascent entrepreneurs believe that external influences constrain their behaviour (i.e. a lack of perceived controllability) (Urbig and Monsen, 2012). Prior experience of establishing or running one's own business has been found to enhance ESE, as it provides practical experience and opportunities for learning (Zhao et al, 2005; Lee et al. 2016). More general work experience has also been found to influence ESE (e.g. Farashah, 2015). From this, ESE might also be expected to increase with age as experience is accumulated. Similarly, education and training have been found to enhance ESE of both undergraduate and postgraduate students, allowing for the development of 'enactive mastery' by using live case studies and plans as well as vicarious learning via studying successful entrepreneurs (Wilson et al, 2007; Gielnik et al., 2017). The evidence regarding the effect of gender is mixed. Whilst the general finding is that women display 
lower ESE than men on average (Newman et al, 2019), some studies have found no effect (Mueller and Dato-On, 2008).

Whilst the effects of social identity and of experience (both of entrepreneurial activity and of running a business), training and gender on ESE have attracted much attention, they have largely been considered in isolation. However, there are strong a priori reasons to expect that ESE will be influenced in different ways by different combinations of antecedents. First, Fauchert and Gruber's (2011) types of founders' social identities have tended to be treated as separate in subsequent studies. However, they are not necessarily mutually exclusive. Fauchert and Gruber's (2011) results included a number of founders, around a fifth, with a "hybrid" identity, displaying characteristics belonging to more than one of the primary identity types (mainly Darwinian and Communitarian); Alsos et al (2016) found correlations between measures of social identity types. This suggests there would be benefit to exploring if and how social identity types combine to influence ESE. Second, the effect of particular social identities will be influenced by other antecedents of ESE. As a Darwinian identity places weight on learning and a "professional" approach, its effects would be magnified when combined with entrepreneurial learning and potentially prior experience and entrepreneurial activity, as these offer ways to learn. Such interactions with Communitarian or Missionary identity might reduce ESE, as expectations of how achievable a communitarian aim is is revised in light of learning or experience. In other words, the effect of a particular identity will be conditional on the presence (or absence) of other factors. Such interdependencies between variables can only be captured in regressions by introducing interaction terms, but there are practical limitations on how many interactions can be introduced. An approach based on configurations, such as FSQCA, specifically allows more complex causal relationships to be identified than can be found in linear regression approaches. Our expectation is that social identity will influence ESE on its own, but also 
in combination with other antecedents. Specifically, drawing on the discussion above, we expect the effect of a Darwinian identity to combine with entrepreneurial learning and experience. However, they need not all interact with each other; rather there could be multiple combinations of identity, learning and experience which are associated with greater ESE. Similarly, the effects of Communitarian and Missionary identity on ESE will be influenced by other antecedents, but here we expect experience and education to reduce ESE.

\section{Fuzzy Set Qualitative Comparative Analysis (FSQCA)}

Fuzzy Set Qualitative Comparative Analysis (FSQCA), (Ragin, 2008; Scheider and Wagemann 2012) allows causal factors to operate in combination with each other to lead to an outcome; different combinations of factors to lead to the same outcome (known as equifinality), and for individual factors to have opposing effects depending on which other factors they are combined with (e.g. Wagemann and Schneider, 2010).

The goal of FSQCA is to identify variables ('conditions') or groups of variables ('configurations' or 'relations') which are either necessary or sufficient for the outcome to occur. A necessary condition is one where the outcome cannot be achieved without it, but its presence on its own is not enough to produce the outcome. A sufficient condition is one where the outcome always occurs if it is present, but other conditions may also produce the same outcome. As Legewie (2013) notes, in real data a few cases will deviate from the general necessity or sufficiency relations. To assess the degree to which groups of variables (usually referred to as relations) are associated with the outcome variable, two fit measures are used: consistency and coverage. Consistency refers to the degree to which a condition or combination of conditions relates to an outcome within the data. Conceptually it is similar to significance in a statistical model. The higher the value (closer to 1) the more consistent the 
relationship is in the data. Coverage provides a measure of relevance, broadly similar to $\mathrm{R}$ squared in regression models

\section{Data and results}

\subsection{Data collection and measures}

Whilst the Brändle et al. (2018) employ data from the German GUESSS, this paper draws upon the 2016 UK sample of the GUESSS. For an overview of the UK data, see Saridakis et al. (2016). Our aim in doing so is to build on Brändle et al's (2018) findings by employing a complementary method of analysis on a related but separate sample. We restrict our sample to nascent entrepreneurs, i.e. those who are currently trying to start a business, or become self-employed but do not already run a business or are self-employed. ESE is of particular importance for nascent entrepreneurs as it can compensate for a lack of direct experience and give greater confidence in their abilities (Engel et al., 2014; Dimov, 2010). This may be of particular significance for younger people at the start of their careers with little or no work experience, as their ESE may be enhanced by entrepreneurship education.

The sample contains 120 nascent entrepreneurs. Removing non-British respondents would eliminate possible confounding effects of national culture, but would also reduce the sample size from 120 to 68 . Whilst FSQCA can accommodate small sample sizes, a sample size of 68 only just exceeds the minimum sample size of 50 cases for 8 variables suggested by Marx (2006). Running the analysis on 68 cases produced a total of 17 different configurations. Following Brändle et al. (2018), measures for Darwinian, Communitarian and Missionary entrepreneurial social-identity, ESE, Entrepreneurial Learning and Perceived Controllability were extracted from the UK GUESSS data. The Entrepreneurial Learning scale captures how far a respondent sees that their studies have developed their 
entrepreneurial skills. The Perceived Controllability scale captures belief in ability make things happen. Sources of the scales used in the GUESSS survey are shown in table 1.

\section{Table 1 here.}

Additionally, respondents' ages and gender are included as conditions. Gender was coded initially as $1=$ male and $0=$ female. Age has been used as a control variable in studies of ESE, but we use it as an indicator of accumulated experience. A binary variable for age was also created, based on the median age of 23 years old. This is two years above the usual minimum graduation age. Whether the respondent had engaged in any of a range of entrepreneurial activities relating to their current business idea (using a list drawn from GEM and the Panel Study of Entrepreneurial Dynamics, employed by Shirokova et al 2016) were also extracted, along with whether the respondent had set up a business before, which we label as prior experience. Reliability and validity measures are given in the appendix.

\subsection{Fuzzy sets and calibration}

Prior to running the FSQCA, the variables are transformed into "fuzzy" measures. As opposed to a crisp set, in which observations are unambiguously allocated as either members of a set or not members of it, fuzzy sets give an indication of the degree to which an observation falls into a set.

Direct calibration as described in Ragin (2008: Chapter 5), was used to create the fuzzy scores for variables measured on a scale. Such calibration requires three threshold values to be defined: for full membership of the set, full non-membership of the set and the crossover point (or point of maximum ambiguity). Values of $6.5,1.5$ and 4 respectively were used for constructs measured on 7 point scales. The categorical variables (age and entrepreneurial activities engaged in) were also transformed into fuzzy scores where definite membership was coded as 0.95 and definite non-membership as 0.05 .

\subsection{Results}


The analysis was run using the FSQCA 3.0 software (Ragin, 2017). First we test for necessary conditions (i.e. conditions which form a superset of the outcome). Following prior literature (e.g. Kimmitt et al, forthcoming) we use a consistency score of above 0.95 to indicate a necessary condition. Although three conditions come close to this (Darwinian, identity, Communitarian identity and Perceived Controllability with consistency scores $\approx 0.9$ ) none exceed the benchmark. This implies that the relationship between ESE and its antecedents is more complex than a linear model would suggest. Following Ragin (2008) the results presented in Table 2 combine information from both the parsimonious and the intermediate solutions: the presence of factor being a core condition is denoted by $\bullet$, the absence of a factor being a core condition is shown by $\otimes$, with $\bullet$ and $\otimes$ denoting presence being a contributing condition and absence being a contributing condition respectively. An empty cell indicates that the condition has no effect.

\section{Table 2 here}

Table 1 shows 4 configurations. In none of the configurations does either Darwinian or Communitarian identity appear as a core condition; rather they both appear in all configurations, and as peripheral conditions. This is in contrast to prior studies (e.g. Brändle et al., 2018) which have assumed that that different social identities are direct but independent determinants of ESE, and echoes findings of hybrid identities (e.g. Fauchert and Gruber, 2011; Alsos et al, 2016). Solution 1 includes having engaged in entrepreneurial activity as a core condition with entrepreneurial learning, Darwinian and Communitarian identities as peripheral conditions. The importance of entrepreneurial activity is intuitive perceptions of self-efficacy become clearer in the light of experience. However, that experience has an effect only in combination with learning and identifying as an entrepreneur. This is consistent with the influence of learning from experience on selfefficacy (e.g. Bandura, 1997). 
In configuration 2, the effect of activity is replaced by (vicarious) experience through entrepreneurial learning as a core condition, but only in association with perceived controllability (if the environment is controllable then what has been learned can be more easily applied) and having less accumulated experience, perhaps implying youthful confidence (or over-confidence). Again, both Darwinian and Communitarian identity appear as peripheral influences. Given that Darwinian entrepreneurs are expected to put more store in professional competence, it was expected that entrepreneurial learning and Darwinian identity would appear in the same configuration. However, this is only partially reflected in configurations 1 and 2. Darwinian identity and entrepreneurial activity appear in configuration 1 and Darwinian identity and education in configuration 2. However, Communitarian identity also appears in those configurations. Configurations 1 and 2 together suggest that different pathways to self-efficacy suggested by socio-cognitive theory (through learning and through mastery experience) operate independently as they tend to appear in different configurations.

In configuration 3, perceived controllability, being male and having accumulated experience are core conditions, supported by Darwinian and Communitarian identity. Neither learning nor entrepreneurial activity are included in this configuration, perhaps being replaced by more general life experience. Being male is also a core condition of this configuration. Uniquely among the configurations identified, no condition relating to learning from experience or from others (pathways to efficacy suggested by SCT) is included. Rather it appears to reflect an innate confidence in ability, as long as the environment is believed to be controllable, that the respondent is male and ascribes to being an entrepreneur.

The final configuration is similar to configuration 1 but with entrepreneurial learning replaced as a peripheral condition by perceived controllability and being male. 
Entrepreneurial activity is the sole core condition in the configuration, supported by

Darwinian and Communitarian identity, being male and perceived controllability.

The over-arching conclusion that can be drawn from Table 1 is that there are multiple different routes to self-efficacy. Darwinian and Communitarian self-identity appear in combination with learning and activity, but play a secondary role. Entrepreneurial activity, learning, perceived controllability and age appear more central to ESE. These routes are consistent with our expectations based on the literature, but would not have been revealed by a linear regression approach and thus contribute to our understanding of self-efficacy among nascent entrepreneurs. The results also offer a suggestion as to why results on the effect of gender on ESE are mixed (e.g. Newman et al., 2019); we find one configuration where being male has an effect on increasing ESE, which is a general but not consistent finding, but also two others where gender has no influence.

\section{Conclusions and implications}

ESE has received increased attention in the literature and become a focus of attention for those examining entrepreneurial start-up (Dalbourg and Wincent, 2014; Schmutzler et al., 2018). In this paper, we have highlighted the complexities in the relationship between ESE and its antecedents and in doing so, contribute to the literature that examines the relationship between social identity, ESE and nascent entrepreneurship. Our analysis shows that, although they influence ESE, none of antecedents previously identified in the literature: prior experience, entrepreneurial learning and perceived controllability, have a consistent effect on ESE. Rather the relationship is better considered through a configurational lens which allows the equifinal nature of the relationship to show through. Social identity has a consistent effect insofar as Darwinian and Communitarian identity appear in all of the configurations found. This implies that models which report direct effects can only reveal part of the story. 
Our findings also suggest that it is ascribing to being an entrepreneur which has an effect on ESE, rather than the type of entrepreneurial identity. Social identity theory (Tajfel and Turner, 1979) suggests that individuals define a sense of self in relation to social groups or categories. Our results show that such groups are defined in terms of being an entrepreneur, rather than being a particular type of entrepreneur. In other words, the link is rooted in perception: identifying as an entrepreneur is associated with greater ESE, but such an identity is not sufficient on its own. Future research could explore the robustness of these links further using alternative operationalisations of founder's social identity.

Whilst our results support Brändle et al's (2018) proposed link between ESE and identity, they suggest that ESE is not a core causal condition; it is necessary but not sufficient. This is in contrast to previous literature which (implicitly) suggests that identity plays a central role and so illustrates the value of generalization and extension replication studies.

Our analysis finds that, for UK nascent entrepreneurs, ESE is influenced more by engaging in entrepreneurial activity and entrepreneurial learning, and by perceived controllability all of which are factors relating to social cognitive theory, than by entrepreneurial social identity. Accumulated experience is also a core contributing condition. However it has different effects in different configurations. Older nascent entrepreneurs in our sample may benefit from greater knowledge and experience (if male and if the environment is seen as controllable). Conversely, younger nascent entrepreneurs may benefit from the "arrogance of youth", but again only if the environment in controllable and they have received entrepreneurship training. This finding illustrates both the ability of a configurational approach to allow the same condition to operate in different ways (i.e. equifinality), but also reflects earlier findings that the desire to start a business tends to diminish with age, but experience increases with age (Laguna, 2013). 
We offer a few caveats regarding how far our findings can be generalised. First, our sample is deliberately limited to university students as a replication study. Future studies might extend these findings beyond a student sample. Further studies may also consider the effect of geographical location on ESE, given its influence on entrepreneurial cultures (Parkinson et al, forthcoming). We have demonstrated that ESE can be achieved through a number of different routes. The implication is that ESE will be difficult to influence by targeting particular antecedents in isolation. It suggests that a combination of antecedents, learning, activity and perceived controllability being chief among them, need addressing if ESE (and hence entrepreneurial intention) is to be enhanced.

\section{Funding}

This research did not receive any specific grant from funding agencies in the public, commercial, or not-for-profit sectors.

The UK GUESSS data collection was funded by Kingston University Business School's research fund.

\section{References}

Ajzen, I. 2002. Perceived behavioural control, self-efficacy, locus of control and the theory of planned behaviour. Journal of Applied Social Psychology, 32, 665-683.

Alsos, G.A., Clausen, T.H., Hytti, U. and Solvoll, S. 2016. Entrepreneurs' social identity and the preference of causal and effectual behaviours in start-up processes. Entrepreneurship and Regional Development, 28, 3-4, 234-258. 
Arenius, P., Engel, Y. and Klyver, K. 2017. No particular action needed? A necessary condition analysis of gestation activities and firm emergence. Journal of Business Venturing Insights, 8, 87-92.

Bandura, A. 1997. Self-efficacy: The exercise of control, New York: W.H. Freeman

Brändle, L., Berger, E.S.C., Golla, S., Kuckertz, A., 2018. I am what I am - How nascent entrepreneurs' social identity affects their entrepreneurial self-efficacy. Journal of Business Venturing Insights, 9, 17-223.

Chen, G., Greene, P. and Crick, A. 1998. Does entrepreneurial self-efficacy distinguish entrepreneurs from managers? Journal of Business Venturing, 13, 295-316.

Dalborg, C. and Wincent, J. 2014. The idea is not enough: The role of self-efficacy in mediating the relationship between pull entrepreneurship and founder passion - a research note. International Small Business Journal, 33, 8, 974-984.

Dimov, D. 2010. Nascent entrepreneurs and venture emergence: opportunity confidence, human capital, and early planning. Journal of Management Studies, 47, 1123-1153.

Engel, Y., Dimitrova, N.G., Khapova, S.N. and Elfring, T. 2014. Uncertain but able: entrepreneurial self-efficacy and novices' use of expert decision-logic under uncertainty. Journal of Business Venturing Insights, 1, 12-17. 
Farashah, A. 2015. The effects of demographic, cognitive and institutional factors on development of entrepreneurial intention: Toward a socio-cognitive model of entrepreneurial career. Journal of International Entrepreneurship, 13, 452-476.

Fauchert, E. and Gruber, M. 2011. Darwinians, communitarians and missionaries: the role of founder identity in entrepreneurship. Academy of Management Journal, 54, 935-957.

Fiss, P. 2007. A set-theoretic approach to organizational configurations. Academy of Management Review, 32(4), 1180-1198.

Fiss, P. 2011. Building better causal theories: A fuzzy set approach to typologies in organizational research, Academy of Management Journal, 54(2), 393-420.

Fiss, P.C., Sharapov, D. and Cronqvist, L. 2013. Opposites attract? Opportunities and challenges for integrating large-n QCA and econometric analysis, Political Research Quarterly, 66(1), 191-198.

Forbes, D.P. 2005. The effects of strategic decision-making on entrepreneurial self-efficacy, Entrepreneurship Theory and Practice, 29. 599-625.

Fornell, C. and Larcker, D. 1981. Evaluating structural equation models with unobservable variables and measurement error, Journal of Marketing Research, 18(1), 39-50. 
Gielnik, M., Uy, M.A., Funken, R. and Bischoff, K.M. (2017). Boosting and sustaining passion: a long-term perspective on the effects of entrepreneurship training, Journal of Business Venturing, 32, 334-353.

Kevill, A., Trehan, K. and Easerby-Smith, M. 2017. Perceiving ‘capability’ within dynamic capabilities: The role of owner-manager self-efficacy, International Small Business Journal, 35(8), 883-902.

Kickul, J., Gundry, L.K., Barbosa, S.D. and Whitcanack, L. 2009. Intuition versus analysis? Testing differential models of cognitive style on entrepreneurial self-efficacy and the new venture creation process, Entrepreneurship Theory and Practice, 33, 439-453.

Kimmitt, J., Muñoz, P. and Newbery, R. forthcoming. Poverty and the varieties of entrepreneurship in the pursuit of prosperity, Journal of Business Venturing, https://doi.org/10.1016/j.jbusvent.2019.05.003

Krause, R., Acharya, A. and Covin, J. 2014. Here I come to save the day: Proposing necessary and sufficient conditions for founder-CEO comeback, Journal of Business Venturing Insights, 1-2, 26-30

Laguna, M. 2013. Self-efficacy, self-esteem and entrepreneurship among the unemployed. Journal of Applied Social Psychology, 43, 253-262.

Lee, C., Hallak, R. and Sardeshmukh, S. 2016. Innovation, entrepreneurship and restaurant performance: a higher order structural model. Tourism Management, 53, 215-288 
Legewie, N. 2013. An introduction to applied data analysis with qualitative comparative analysis (QCA), Forum Qualitative Sozialforschung / Forum: Qualitative Social Research, 14(3), article 15 (http://nbn-resolving.de/urn:nbn:de0114-fgs1303154)

Levenson, H. 1973. Multidimensional locus of control in psychiatric patients, Journal of Consulting and Clinical Psychology, 41, 397-404.

Liñán F. 2008. Skill and value perceptions: how do they affect entrepreneurial intentions? International Entrepreneurship and Management Journal, 4, 257-272.

Marx, A. 2006. Towards more robust model specification in QCA: Results from a methodological experiment. COMPASS Working Paper, 43, http://www.compasss.org/wpseries/Marx2006.pdf

Miao, C., Qian, S. and Ma, D. 2017. The relationship between entrepreneurial self-efficacy and firm performance: a meta-analysis of main and moderator effects. Journal of Small Business Management, 55(1), 87-107

Misangyi, V.F., Greckhamer, T., Furnari, S., Fiss, P.C., Crilly, D., Aguilera, R. 2016. Embracing causal complexity: The emergence of a neo-configurational perspective, Journal of Management, 43(1), 255-282.

Mueller, S. and Dato-On, M. 2008. Gender-role orientation as a determinant of entrepreneurial self-efficacy. Journal of Developmental Entrepreneurship, 13, 3-20 
Newman, A., Obschonka, M. Schwarz, S. Cohen, M. and Nielsen, I. 2018. Entrepreneurial self-efficacy: A systematic review of the literature on its theoretical foundations, measurement, antecedents and outcomes, and an agenda for future research. Journal of Vocational Behavior, https://doi.org/10.101016/j.jvb.2018.05.012.

Parkinson, C., Nowak, V., Howorth, C. and Southern, A. forthcoming. Multipartite attitudes to enterprise: A comparative study of young people and place, International Small Business Journal, DOI: 10.1177/0266242619892829.

Ragin, C. 1987. The comparative method: Moving beyond qualitative and quantitative strategies, Berkley, California: University of California Press

Ragin, C. 2008. Redesigning Social Enquiry: Fuzzy sets and beyond, Chicago: University of Chicago Press.

Ragin, C. 2017. Fuzzy-Set/Qualitative Comparative Analysis 3.0 software, available from http://www.fsqca.com

Saridakis, G., Iskandarova, M. and Blackburn, R. 2016. Student entrepreneurship in Great Britain: The British report of the 2016 GUESSS project, Kingston: Small Business Research Centre, Kingston University.

Schmutzler, J., Andonova, V. and Diaz-Serrano, L. 2018. How context shapes entrepreneurial self-efficacy as a driver of entrepreneurial intentions: a multilevel approach, 
Entrepreneurship Theory and Practice (online ahead of publication) https://doi.org/10.1177/1042258717753142

Schneider, C. and Wagemann, C. 2012. Set-theoretic methods for the social sciences: a guide to qualitative comparative analysis, Cambridge: Cambridge University Press.

Shirokova, G., Osiyevsky, O., and Bogatyreva, K. 2016. Exploring the intention-behavior link in student entrepreneurship: moderating effects of individual and environmental characteristics, European Management Journal, 34, 386-399.

Sieger, P., Gruber, M., Fauchart, E., Zellweger, T. 2016. Measuring the social identity of entrepreneurs: scale development and international validation. Journal of Business Venturing, $31,542-572$.

Souitaris, V., Zerbinati, S., Al-Laham, A. 2007. Do entrepreneurship programmes raise entrepreneurial intention of science and engineering students? The effect of learning, inspiration and resources. Journal of Business Venturing, 22, 566-591.

Stroe, S., Parida, V. and Wincent, J. 2018. Effectuation or causation: An fsqca analysis of entrepreneurial passion, risk perception and self-efficacy. Journal of Business Research, 89, $265-272$.

Tajfel, H. 1972. Social Categorization (La catégorisation sociale) In: Moscovici, S. (Ed.) Introduction à la psychologie sociale, Larousse, Paris, pp272-302. 
Tajfel, H. and Turner, J.C. 1979. An integrative theory of intergroup conflict. In W.G. Austin \& S. Worschel (Eds).The social psychology of intergroup relations (pp. 33-47)

Urbig, D. and Monsen, E. 2012. The structure of optimism: controllability affects the extent to which efficacy beliefs shape outcome expectancies. Journal of Economic Psychology, 33, 854-867.

Wagemann, C. and Schneider, C. 2010. Qualitative comparative analysis (QCA) and fuzzy sets: Agenda for a research approach and a data analysis technique. Comparative Sociology, 9(3), 376-396.

Walker, R., Brewer, G., M.J. Lee, Petrovsky, N. and van Witteloostuijn, A. 2018. Best practice recommendations for replicating experiments in public administration, Journal of Public Administration Research and Theory, https://doi.org/10.1093/jopart/muy047

Woodside, A. 2016. The good practices manifesto: Overcoming bad practices pervasive in current research in business. Journal of Business Research, 69(2), 365-381.

Wilson, F., Kickul, J, and Marlino, D. 2007. Gender, entrepreneurial self-efficacy and entrepreneurial career intentions: Implications for entrepreneurship intentions. Entrepreneurship Theory and Practice, 31, 387-406.

Zhao, H., Seibert, S. and Hills, G. 2005. The mediating role of self-efficacy in the development of entrepreneurial intentions. Journal of Applied Psychology, 90, 1265-1272. 


\section{Appendix}

Scale reliability and validity

As shown in Table A1, all Cronbach's alpha and Composite Reliability values are over 0.7 and Average Variance Extracted (AVE, a measure of convergent validity) over 0.5.

\section{Table A1 here}

Discriminant validity is assessed using the Fornell and Larcker (1981) criterion that the square root of the AVE should be greater than the correlations between constructs. As shown in Table A2, this holds for most of the constructs. However, there is a strong correlation between Missionary and Communitarian identity constructs $(r=0.744)$ and the square root of the AVE for Missionary identity only just exceeds this.

\section{Table A2 here}

This is to some extent to be expected; Sieger et al. (2016) study found that when responses were pooled across English speaking GUESSS countries, the items did not load as expected onto three dimensions, but four. Using just data from the UK, the discriminant validity assessment suggests that the Communitarian and Missionary constructs are not distinct. However, if the Missionary items are dropped and an Exploratory Factor Analysis is run on the Darwinian and Communitarian items, they load as expected onto two factors. Given this, we drop the Missionary dimension of Founders' Social Identity, as in the UK at least it does not appear to be distinct from the Communitarian construct. 
Table A1. Reliability and Convergent Validity

\begin{tabular}{|l|l|l|l|}
\hline & Cronbach's alpha & $\begin{array}{l}\text { Composite } \\
\text { Reliability }\end{array}$ & $\begin{array}{l}\text { Average Variance } \\
\text { Extracted }\end{array}$ \\
\hline Darwinian & 0.816 & 0.877 & 0.590 \\
\hline Communitarian & 0.886 & 0.920 & 0.757 \\
\hline Missionary & 0.816 & 0.875 & 0.584 \\
\hline ESE & 0.894 & 0.904 & 0.613 \\
\hline Entrepreneurial learning & 0.896 & 0.923 & 0.707 \\
\hline Perceived controllability & 0.685 & 0.843 & 0.644 \\
\hline
\end{tabular}


Table A2. Discriminant Validity - correlation and AVE

\begin{tabular}{|l|c|c|c|c|c|c|c|c|}
\hline & 1 & 2 & 3 & 4 & 5 & 6 & 7 & 8 \\
\hline 1 Darwinian & $\mathbf{0 . 7 6 8}$ & & & & & & & \\
\hline 2 Communitarian & 0.462 & $\mathbf{0 . 8 7 0}$ & & & & & & \\
\hline 3 Missionary & 0.514 & 0.761 & $\mathbf{0 . 7 6 2}$ & & & & & \\
\hline 4 ESE & 0.463 & 0.434 & 0.401 & $\mathbf{0 . 7 8 3}$ & & & & \\
\hline 5 Entrepreneurial learning & 0.241 & 0.249 & 0.136 & 0.321 & $\mathbf{0 . 8 4 1}$ & & & \\
\hline 6 Perceived controllability & 0.257 & 0.158 & 0.210 & 0.442 & 0.245 & $\mathbf{0 . 8 0 2}$ & & \\
\hline 7 Entrepreneurial activity & 0.038 & 0.149 & 0.146 & 0.100 & 0.118 & 0.168 & - & \\
\hline 8 Prior experience & -0.085 & -0.036 & -0.066 & -0.026 & 0.020 & -0.050 & 0.191 & - \\
\hline 9 Accumulated experience & 0.043 & 0.015 & -0.003 & 0.130 & -0.090 & 0.147 & 0.042 & 0.150 \\
\hline
\end{tabular}

Square roots of AVE values are shown in bold. - denotes single question variables so an AVE cannot be calculated 
Table 1. Measures employed by the GUESSS survey

\begin{tabular}{|l|l|l|}
\hline Construct & Source & $\begin{array}{l}\text { Number } \\
\text { of items }\end{array}$ \\
\hline Darwinian social identity & Sieger et al. $(2016)$ & 5 \\
\hline Communitarian social identity & Sieger et al. $(2016)$ & 5 \\
\hline Missionary social identity & Sieger et al. (2016) & 5 \\
\hline Entrepreneurial Self-Efficacy & $\begin{array}{l}\text { Chen } \text { et al. } \text { (1998); Forbes (2005); Liñán } \\
(2008) ; \text { Zhao } \text { et al., 2005; Kickul } \text { et al. } \\
(2009)\end{array}$ & 7 \\
\hline Entrepreneurial Learning & Souitaris et al. (2007) & 5 \\
\hline Perceived Controllability & Levenson (1973) & 3 \\
\hline
\end{tabular}


Table 2 FSQCA intermediate solution

\begin{tabular}{|l|c|c|c|c|}
\hline & 1 & 2 & 3 & 4 \\
\hline Darwinian & $\bullet$ & $\bullet$ & $\bullet$ & $\bullet$ \\
\hline Communitarian & $\bullet$ & $\bullet$ & $\bullet$ & $\bullet$ \\
\hline Perceived Controllability & & $\bullet$ & $\bullet$ & $\bullet$ \\
\hline Entrepreneurial Learning & $\bullet$ & $\bullet$ & & \\
\hline Gender (Male) & & & $\bullet$ & $\bullet$ \\
\hline Accumulated experience & & $\bigotimes$ & $\bullet$ & \\
\hline Prior Experience & & & & \\
\hline Entrepreneurial Activity & $\bullet$ & & & $\bullet$ \\
\hline Raw coverage & 0.317 & 0.367 & 0.252 & 0.241 \\
\hline Unique Coverage & 0.047 & 0.171 & 0.092 & 0.015 \\
\hline Consistency & 0.967 & 0.990 & 0.984 & 0.996 \\
\hline Overall Coverage & 0.621 & & & \\
\hline Overall Consistency & 0.973 & & & \\
\hline
\end{tabular}

